What is the nature of purpura? Detail the states of the system with which it may be accompanied, and the appearances observed in the internal organs in fatal cases. Give an outline of its treatment.

Detail the symptoms, diagnosis, and causes of delirium tremens. How should it be treated?

Detail the general symptoms and terminations of pneumonia, State the physical signs which indicate its different stages, and the appropriate treatment of each.

Describe the paroxysm of angina pectoris. Specify the derangements of the system, functional and organic, with which it may be connected.

Specify the various functional and structural lesions which give rise to ileus. Describe the progressive changes that take place in the intestinal canal in cases in which an invaginated portion is discharged.

State the varieties of small-pox. Detail the symptoms and treatment of confluent small pox.

What are the symptoms by which granular degeneration of the kidneys may be recognised? What is the condition of the urine in this disease? Mention the secondary lesions which occur in its progress.

Specify the nature of the internal lesions with which rheumatism is frequently complicated.

Detail the symptoms, diagnosis, and terminations of scirrhus of the pylorus.

State the various causes by which pneumothorax may be induced. Detail its physical signs and diagnosis, and give an outline of its treatment.

What are the symptoms of diabetes? Detail the mode of treatment, remedial and dietetic.

Give the general symptoms and physical signs of empyema. State the general measures to be adopted with the view of promoting the absorption of the fluid, and the circumstances which render the evacuation of the fluid by tapping expedient.

What are the symptoms, causes, and treatment of scurvy?

Describe the external characters of the scrofulous diathesis, and the prophylactic treatment of tuberculous cachexia.

\section{DISPENSARY EXTORTIONS.}

\section{To the Editor of THE LANCET.}

SIn :-I take the liberty of sending you a copy of a letter which $I$ published in the "Times" of Saturday, and which I shall feel obliged by your inserting in the next number of your Journal.

\section{Yours obediently,}

\section{J. H. Houahton.}

"To the Governors of the Aldersgate Goneral Dispensary.

" My Lords, Ladies and Gentlemen:-I and other candidates for the office of apothecary to your institution having received a letter from your collector, of which the following is a copy, I take the liberty of submitting it to your notice.

$$
\begin{aligned}
& \text { 46 85, Aldersgate-street, } \\
& \text { 66 \& Aug. 28, } 1839 .
\end{aligned}
$$

"6 'Sir:-I shall remain at home this even. ing till nine o'clock, for the receipt of subscriptions. Yours obediently,

$$
\text { “' 'H. Piper.' }
$$

"As I cannot conscientiousiy become a party to the means therein implied for obtaining the office, I beg to withdraw from the contest, and to return my best thanks to those governors who have kindly honoured me with their support. I remain, my Lords, Ladies, and Gentlemen, your obedient servant,

\section{“6 14, Carthusian-street,}

“Aug. 30, 1839."

\section{BRITISH MEDICAL ASSOCIATION.}

Meeting of Council, Sept. 10, 1839.

Dr. Webster, President, in the Chair.

THE minutes of the last meeting were read and confirmed.

Dr. Southwood Smith having been proposed and seconded, was unanimously elected a nember of the Association.

A letter was read from J. M. Coley, of Bridgnorth, on the subject of illegal practitioners.

Extracts from a letter from Dr. Maunsell were read and commented on.

The remaining portion of the evening was occupied in preparing the lists of those eligible as officers and councillors for the ensuing year, \&c.-(See advertisement.)

\section{SUBJECTS FOR DISSECTION.}

A correspondent, who signs " An Anatomical Student," has forwarded to us a letter on the scarcity of subjects for dissection, from which we make the following extracts:

"The loud complaints made last session for the want of subjects cannot be unknown to you ; some dissecting-rooms were for days without any part of a subject being in them. Lecturers on anatomy were obliged to postpone certain subjects until a body should come in, and at other times demonstrate, and even lecture from dry preparations. These are facts for which I can vouch as they came under my notice, and I would ask if such a state is to continue? I believe the supply nerer was so deficient as last winter. I asked some teachers how it was 